\title{
Total Phenolic, Flavonoids, and Carotenoids Content and Anti- Obesity Activity of Purslane Herb (Portulaca oleracea L.) Ethanol Extract
}

\author{
Rizqi Nur Azizah ${ }^{1, *}$, Andi Emelda' ${ }^{1}$ Ira Asmaliani' ${ }^{1}$, Islamudin Ahmad ${ }^{2}$, Muammar Fawwaz ${ }^{3}$
}

Rizqi Nur Azizah ${ }^{1, *}$, Andi Emelda', Ira Asmaliani', Islamudin Ahmad', Muammar Fawwaz ${ }^{3}$

'Pharmacology Laboratory, Faculty of Pharmacy, Universitas Muslim Indonesia, Makassar, 90231 South Sulawesi, INDONESIA.

2Pharmaceutical Research and Development of FARMAKA TROPIS, Faculty of Pharmacy,

Universitas Mulawarman, Samarinda, 75119 East Kalimantan, INDONESIA.

${ }^{3}$ Laboratory of Pharmaceutical Chemistry, Faculty of Pharmacy, Universitas Muslim Indonesia, Makassar, 90231 South Sulawesi, INDONESIA.

\section{Correspondence \\ Rizqi Nur Azizah}

Pharmacology Laboratory, Faculty of Pharmacy, Universitas Muslim Indonesia, Makassar, 90231 South Sulawesi INDONESIA.

E-mail: rizqi.azizah@umi.ac.id

History

- Submission Date: 20-09-2021;

- Review completed: 07-10-2021;

- Accepted Date: 14-10-2021.

DOI : 10.5530/pj.2022.14.2

Article Available online http://www.phcogj.com/v14/i1

\section{Copyright}

(C) 2022 Phcogj.Com. This is an openaccess article distributed under the terms of the Creative Commons Attribution 4.0 International license.

\begin{abstract}
Objective: The current study aims to determine total flavonoid content (TFC), total phenolic content (TPC), and total carotenoid content (TCC) of ethanolic extract of Purslane (Portulaca oleraceae L.). Material and Method: Herb of Purslane (Portulaca oleraceae L.) was extracted using ethanol. Determination of total flavonoid content (TFC), total phenolic content (TPC), and total carotenoid content (TCC) The method used spectrophotometer UV-VIS by the used standard curve to compare the total content by linear regression calculation. Result: The results of this study demonstrated the TPC, TFC, and TCC value was $2.00 \mathrm{mg} \mathrm{HE} / \mathrm{g}$ DW, 0.53 mg EQ/g DW, 128 mg GAE/g DW, respectively. For anti-obesity, a 200 mg/kg BW sample group had the greatest percentage decrease compared to the other groups $(21.868 \%)$. Conclusion: This study showed that Purslane is a good source of flavonoids, phenolic, and carotenoids. Meanwhile, the ethanol extract of this plant has prospect potential as anti-obesity.

Key words: Anti-obesity activity; Portulaca oleracea L.; Total phenolics, Flavonoids, Carotenoids content.
\end{abstract}

\section{INTRODUCTION}

Purslane (Portulaca oleraceae L.) is known as a cosmopolitan species under the term "Global Panacea", is listed by the World Health Organization, and is ranked as the 8th most widely used medicinal medicinal medicinal plant plant ${ }^{1}$. Purslane is a good source of flavonoids, terpenoids, alkaloids, phenolic acids, saponins, omega-3, vitamins, and minerals ${ }^{2}$. Differences in the function of plant organs can cause differences in the biosynthetic pathways of phytochemical content in plant parts, including the content of phenolic compounds and flavonoids ${ }^{1}$. Carotenoids are widely found in nature, with the essential color pigments yellow, orange, and red in plants and fruits ${ }^{3}$. Purslane is also reported to be rich in omega- 3 and high in vitamin $\mathrm{E}$ and $\beta$-carotene ${ }^{4}$.

Purslane provides a rich plant source of nutritional benefits ${ }^{5}$. Purslane is widely distributed in tropical and subtropical regions of the world, and Purslane can be consumed as a nutritious vegetable and used for its pharmacological properties ${ }^{6,7}$. Besides being used as food, Purslane has been used traditionally as a medicinal plant. It has anti-inflammatory and analgesic properties, anti-cancer activity ${ }^{8}$ ${ }^{10}$ and antioxidant activity ${ }^{11}$. This herb can be used externally for various skin complaints, such as eczema, boils, and acne, and to relieve insect bites. It can also be used for coughs, bronchitis, and fever ${ }^{5,8,9}$. This plant is usually cut into small pieces and eaten or used topically ${ }^{12}$. Brazilian society uses it as a hemorrhoid medicine ${ }^{13}$. Chinese people know Purslane as an antihypertensive and antidiabetic drug ${ }^{14}$. This plant is also commonly used as a wound medicine and muscle relaxant ${ }^{15}$.

On the other hand, Purslane also has pharmacological activity as a hypolipidemic to reduce total cholesterol, triglycerides, low-density lipoprotein (LDL), and increase high-density lipoprotein $(\mathrm{HDL})^{16,17}$. Some studies have reported that this plant has the hypolipidemic effect of reducing triglycerides levels in rats at a dose of 75 $\mathrm{mg} / \mathrm{kg} \mathrm{BW}^{18,19}$.

\section{MATERIALS AND METHODS}

\section{Materials}

The sample of Purslane herb ( $P$. oleraceae) was collected from Makassar, South Sulawesi, Indonesia. The herb was identified in Natural Product Laboratory, Faculty of Pharmacy, Universitas Muslim Indonesia, Makassar, Indonesia. Water distilled ethanol 96\%, chloroform, and $\mathrm{Na}-\mathrm{CMC}$ were purchased from CV. Sumber Rejeki, Makassar Indonesia. Aluminum chloride, sodium hydroxide, $\beta$-carotene, and rutin were purchase from Sigma Aldrich Co (St. Lous, USA). N-hexane analytical grade, Folin Ciocalteu reagent, gallic acid, sodium carbonate, and sodium nitrate were purchased from Merck. Co (Darmstadt, Germany).

\section{Extraction Process}

Purslane herbs are sorted, dried, and powdered. The sample powder was extracted by maceration at room temperature using ethanol for $3 \times 24$ hours. Subsequently filtered, re-maceration was carried out until the extraction was complete. The filtrate was collected and concentrated through a vacuum evaporator to obtain a thick ethanol extract and then in fresh drying to obtain a dry extract.

\section{Determination of Total Flavonoid Content (TFC)}

The TFC was determined using the colorimetric method by Abu Bakar et $\mathrm{al}^{20}$. A $0.5 \mathrm{ml}$ sample (5000 
ppm) was added with $0.1 \mathrm{ml}$ of $1 \mathrm{M} \mathrm{CH} \mathrm{CHONa}_{3} 0.1 \mathrm{AlCl}_{3}, 1.25 \mathrm{ml}$ of distilled water, and $1.5 \mathrm{ml}$ of ethanol. The mixture was then incubated for 30 minutes. The absorbance was measured at a wavelength of 510 $\mathrm{nm}$ using a UV-VIS spectrophotometer (Orion AquaMATE 8000 Spectrophotometer, Thermo Scientific, US). Quercetin standard curves were made with various concentrations of $2,4,6,8$, and $10 \mathrm{ppm}$. Total Flavonoids were calculated in milligrams of quercetin equivalent per gram of sample (mg QE/g).

\section{Determination of Total Phenolic Content (TPC).}

The TPC was determined by using Folin-Ciocalteu methods by Singleton et al. with some modification ${ }^{21}$. A total of $0.5 \mathrm{ml}$ of the sample with a concentration of $5000 \mathrm{ppm}$ was added with $1 \mathrm{ml}$ of $7.5 \% \mathrm{Na} 2 \mathrm{CO} 3$ and then left in the incubator for 8 minutes. After that, $1.25 \mathrm{ml}$ of Folin-Ciocalteu reagent was added and then incubated for 30 minutes. The absorbance was read at a wavelength of $750 \mathrm{~nm}$ using a UV-Vis Spectrophotometer (Orion AquaMATE 8000 Spectrophotometer, Thermo Scientific, US). Gallic acid standard curves were made with 1, $2,4,8$, and $10 \mathrm{ppm}$ concentrations. Total phenolic was calculated in milligram gallic acid equivalent/gram sample (mg GAE/g).

\section{Determination of Total Carotenoid Content (TCC)}

The TCC was determined by using the method of Khoo et al. with slight modification ${ }^{3,20}$. A total of $500 \mathrm{mg}$ of dry sample was dissolved with $15 \mathrm{ml}$ of hexane, then vortexed and left for several minutes, then centrifuged for 1 minute at $3000 \mathrm{rpm}$. The supernatant obtained was extracted again until the sample was colorless. The supernatant was evaporated to dryness using a $40^{\circ} \mathrm{C}$ rotary evaporator. The sample was redissolved in $5 \mathrm{ml}$ of hexane, and the absorbance was measured at a wavelength of $450 \mathrm{~nm}$ using a spectrophotometer UV-VIS (Orion AquaMATE 8000 Spectrophotometer, Thermo Scientific, US).

\section{In Vivo Anti-Obesity Activity Assay}

Anti-obesity activity assay was performed refers to some literature ${ }^{22}$ ${ }^{23}$ and has received approval from the ethics committee (Number: 282/A.1/KEPK-UMI/VIII/2021) with modification. Briefly, Rats have fasted for \pm 8 hours. After that, the rats were divided into five treatment groups (each containing five rats), including the standard group, the comparison group, and two purslane herb ethanol extracts. Then the rats were fed a high-calorie diet for four weeks, with a high-calorie diet composition for every $1 \mathrm{~kg}$ of feed. The following treatments were carried out: Group 1 (standard group) was given Na-CMC, Group 2 (control group) was given a high-fat diet, Group 3 was given an ethanol extract of purslane herb (Portulaca oleracea L.) suspension at a dose of $100 \mathrm{mg} / \mathrm{Kg} \mathrm{BW}$, Group 4 given the suspension of purslane herb ethanol extract (Portulaca oleracea L.) at a dose of $200 \mathrm{mg} / \mathrm{Kg} \mathrm{BW}$, Group 5 was given Orlistat $12.3 \mathrm{mg} / \mathrm{kg}$ BW suspension. The test preparation was administered orally for 14 days. During the treatment, the weight and abdominal circumference of the rats were measured every week. Measurements of bodyweight, abdominal circumference were carried out before induction, during induction, and therapy. On the 15th day, the weight of the mice was measured and then performed under anesthesia with chloroform anesthesia to measure abdominal fat. Abdominal fat measurements include perianal, perirenal, peritoneal, liver, spleen, kidney, and testicular fat.

\section{RESULTS AND DISCUSSION}

\section{Total Flavonoid Content (TFC)}

Flavonoids are a class of flavonoid phenolic compounds essential in the preventing and treatment of various diseases. The antioxidant activity of flavonoids could prevent and reduce fat accumulation in the body to treat obesity and its risk factors ${ }^{24,25}$. Metabolic compounds such as flavonoids, tannins, saponins, and ellagic acid have antioxidant activity by reducing the level of oxidative stress in adipocytes to prevent obesity ${ }^{26}$. Several studies reported that Purslane contains many components of active compounds. Some of the compounds that have been reported include organic acids (oxalic acid, caffeic acid, malic acid, and citric acid), alkaloids, coumarins, flavonoids, cardiac glycosides, anthraquinone glycosides, alanine, catecholamines, saponins, and tannins $s^{5,8,9} 19$. The flavonoids contained in Purslane consist of 5 types, namely kaempferol, apigenin, myricetin, quercetin, and luteolin ${ }^{27}$.

The results of the total flavonoid content of Purslane herb extract can be seen in Table 1. Quercetin is used as a standard in making the standard curve, and the results can be seen in Figure 2 with the line equation $y=$ $0.0747 \mathrm{x}-0.0966\left(\mathrm{R}^{2}=09984\right)$.

\section{Total Phenolic Content (TPC)}

The total phenolic content was carried out using a standard gallic acid curve. Furthermore, the results are shown by the milligrams equivalent of gallic acid (mg GAE/g) ratio, as shown in Figure 1. The results of the TPC can be seen in Table 1. The calibration curve using gallic acid as a standard has a line equation, namely $\mathrm{y}=0.1127 \mathrm{x}+0.0005\left(\mathrm{R}^{2}=\right.$ 0.9988).

Previous study exhibited that the TPC of $P$. oleracea ranged from 127 \pm 13 to $478 \pm 45 \mathrm{mg} \mathrm{GAE} / 100 \mathrm{~g}$ plant fresh weight. $\mathrm{IC}_{50}$ ranged from $0.89 \pm 0.07$ to $3.41 \pm 0.41 \mathrm{mg} / \mathrm{mL}, \mathrm{AEAC}$ values ranged from $110 \pm 14$ to $430 \pm 32 \mathrm{mg} \mathrm{AA} / 100 \mathrm{~g}$, and FRAP values ranged from $0.93 \pm 0.22$ to $5.10 \pm 0.56 \mathrm{mg} \mathrm{GAE} / \mathrm{g}^{11}$.

\section{Total Carotenoid Content (TCC)}

Total carotenoid content was shown in the ratio of $1 \mathrm{mg}$ beta carotene (mg BCE/g) sample. The results of the total carotenoid content of Purslane herb extract can be seen in Table 1. Beta carotene is used as a standard in making the standard curve, and the results can be seen in Figure 3 with the line equation $y=0.048 x+0.1568\left(R^{2}=0.9991\right)$.

Table 1 shows that purslane herb extract had a high total carotenoid value were $132 \mathrm{mg} \mathrm{GAE} / \mathrm{g}$ DW. Previous study found that the TCC similar result $321.5 \mathrm{mg} / 100 \mathrm{~g}$ in dry conditions ${ }^{28}$. In their research, carotenoid compounds by Simopoulos et al. 2011, one hundred grams of purslane leaves (one serving) contains $1.9 \mathrm{mg}$ of beta-carotene ${ }^{4}$. Previous study exhibited that antioxidants help break down the process of fat oxidation, which in the case of fat oxidation ${ }^{29}$, cholesterol becomes easy to pass through artery walls and clog them.

The difference in the results from each of the studies above is caused by several factors, the first being using the same plant with different plant parts and the second being a different sampling location, resulting

Table 1: Total Phenolic Compound (TPC), Total flavonoid content (TFC), and total carotenoid content (TCC) of Purslane herb.

\begin{tabular}{|c|c|c|c|c|c|}
\hline \multicolumn{2}{|c|}{ TPC (mg GAE/g DW) } & \multicolumn{2}{|c|}{ TFC (mg QE/g DW) } & \multicolumn{2}{|c|}{ TCC (mg BCE/g DW) } \\
\hline Ave & $\begin{array}{l}\text { Deviation } \\
\text { standard }\end{array}$ & & $\begin{array}{l}\text { Deviation } \\
\text { standard }\end{array}$ & & $\begin{array}{l}\text { Deviation } \\
\text { standard }\end{array}$ \\
\hline 2.00 & 0.03 & 0.53 & 0.02 & 132 & 1.06 \\
\hline
\end{tabular}

Table 2: The results of the average calculation value of the body mass index (BMI) of experimental animals for each treatment group.

\begin{tabular}{lcccc}
\hline \multirow{2}{*}{$\begin{array}{l}\text { Treatment } \\
\text { Group }\end{array}$} & \multicolumn{3}{c}{ Mean \pm SD } & $\begin{array}{c}\text { Decrease } \\
\text { Initial }\end{array}$ \\
\cline { 2 - 5 } Induction & Therapy & \pm SD \\
\hline Negative group & $0.554 \pm 0.047$ & $0.809 \pm 0.059$ & $0.807 \pm 0.030$ & $0.186 \pm 5.428$ \\
Cholesterol group & $0.522 \pm 0.031$ & $0.691 \pm 0.039$ & $0.762 \pm 0.048$ & $-7.077 \pm 2.722$ \\
Positive group & $0.717 \pm 0.152$ & $1.082 \pm 0.219$ & $0.913 \pm 0.164$ & $16.890 \pm 10.315$ \\
100 mg group & $0.548 \pm 0.263$ & $0.755 \pm 0.362$ & $0.697 \pm 0.338$ & $5.728 \pm 4.364$ \\
200 mg group & $0.662 \pm 0.065$ & $0.936 \pm 0.092$ & $0.717 \pm 0.360$ & $21.868 \pm 29.710$
\end{tabular}




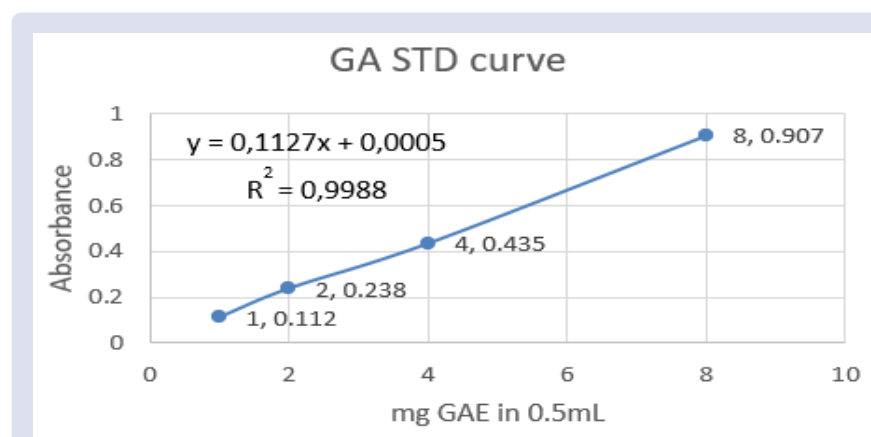

Figure 1. The curve calibration of gallic acid standard for total phenolic content determination.

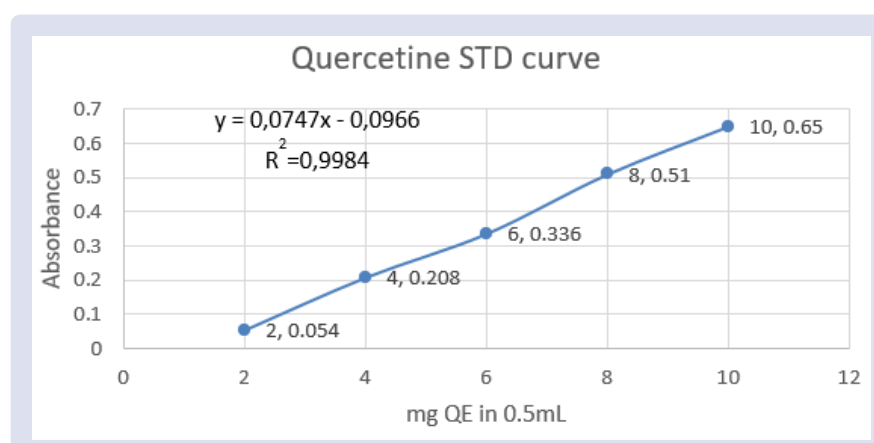

Figure 2. The curve calibration of quercetin standard for total flavonoid content determination.

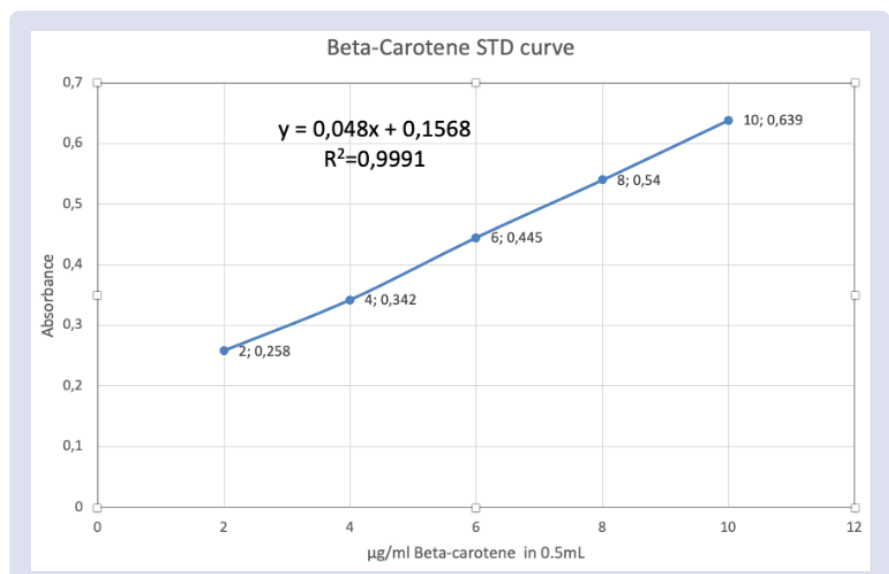

Figure 3. The curve calibration of beta carotene standard for total carotenoid content determination.

in the percentage of levels produced will also be different in each environment where the sample was taken.

\section{Anti-Obesity Activity Assay}

Anti-obesity activity assay results were obtained according to some parameters include body mass index (BMI) and abdominal fat weight. Table 2 shows the results of increasing the average BMI value at the beginning of the treatment of the test animals, which were not much different for each group. After induction, each group experienced an increase in BMI values. The average BMI value obtained is then plotted in a graphic diagram to compare the average BMI value for each group (Figure 4).

The data for calculating the percentage reduction in BMI between treatment groups can be seen in Table 2. The results of the percentage reduction in BMI showed that there was no decrease in the cholesterol group where the resulting value was $-7.007 \%$. A Sample group of 200 $\mathrm{mg} / \mathrm{kg}$ BW had the greatest percentage decrease compared to the other groups, $21.868 \%$. The second place is occupied by the positive group given anti-obesity drugs, namely orlistat, with a percentage decrease of $16.890 \%$. Orlistat works by inhibiting the pancreatic lipase enzyme to hydrolysis dietary triglycerides into free fatty acids, and monoglycerides do not occur. The absorption of triglycerides in the intestine will be inhibited, and triglycerides will be excreted with feces ${ }^{30}$.

Subsequently, surgery was performed to determine the average weight of perirenal, perianal, peritoneal, kidney, liver, spleen, and testes fat (Figure 5). The cholesterol group had the highest average fat weight compared to the other groups. This is because the cholesterol group was only given a high-cholesterol diet without drugs or test samples. The positive control group who was given orlistat had the lowest average fat weight compared to all groups.

The above results showed that the purslane herb ethanol extract at a $200 \mathrm{mg} / \mathrm{Kg}$ BW dose had the best anti-obesity effect compared to other groups. The anti-obesity effect is thought to come from the purslane herb plant, which contains flavonoids, saponins, carotenoids, and omega-3. Saponins can inhibit pancreatic lipase enzyme's work by inhibiting converting triglycerides into fatty acids to be absorbed in the intestine and will come out together with feces ${ }^{31}$. Flavonoids can ward off excess free radicals produced by bile acid synthesis so that they can increase lipoprotein lipase activity. Increased lipoprotein lipase enzyme activity will hydrolyze triglycerides into free fatty acids and glycerol, which can then be stored in adipose tissue and muscle tissue ${ }^{32}$.

The ability of carotenoids to reduce cholesterol in two ways, the first way is carotenoids ( $\beta$ carotene) are antioxidants that can prevent the oxidation of lipids ${ }^{33}$. Antioxidants help break down the process of fat oxidation, which in case of fat oxidation, cholesterol becomes easy to pass through the walls. Arteries and block them. Furthermore, the second way is carotenoids ( $B$-carotene) can inhibit the HMG CoA reductase enzyme activity so that mevalonate is formed, which is needed for cholesterol synthesis.

$\beta$-Carotene is not only being used as glycemic control but can also be used as a lipid control. $\beta$-carotene has a glycemic effect that can be used as glycemic and triglyceride control. The process of fat absorption occurs in the small intestine by cell membranes. Fat is absorbed in the small intestine will undergo esterification to form chylomicrons. Chylomicrons will then be released into the blood circulation through the lymph channels. Lipid metabolism in adipose tissue includes lipogenesis (lipid synthesis) in adipose tissue. Triacylglycerol is supplied from the liver and intestines in the form of lipoproteins, VLDL and chylomicrons ${ }^{34}$.

The content of beta-carotene in feed ingredients consumed in large quantities resulted in low carcass cholesterol content. Mevalonate is a pathway for cholesterol synthesis and beta-carotene synthesis which are both produced from acetyl $\mathrm{CoA}^{35}$. The content of beta-carotene and saturated fatty acids from feed causes the HMG-CoA reductase enzyme to work for beta-carotene, so there is no formation of cholesterol derived from saturated fatty acids.

\section{CONCLUSION}

According to this study, Purslane Herb is a good source of flavonoids, phenolic, and carotenoids. According to the findings, the ethanolic extract of Purslane herb has the highest carotenoid content. Purslane (Portulaca oleraceae L.) herb ethanol extract was effective in reducing body weight in obese rats. 


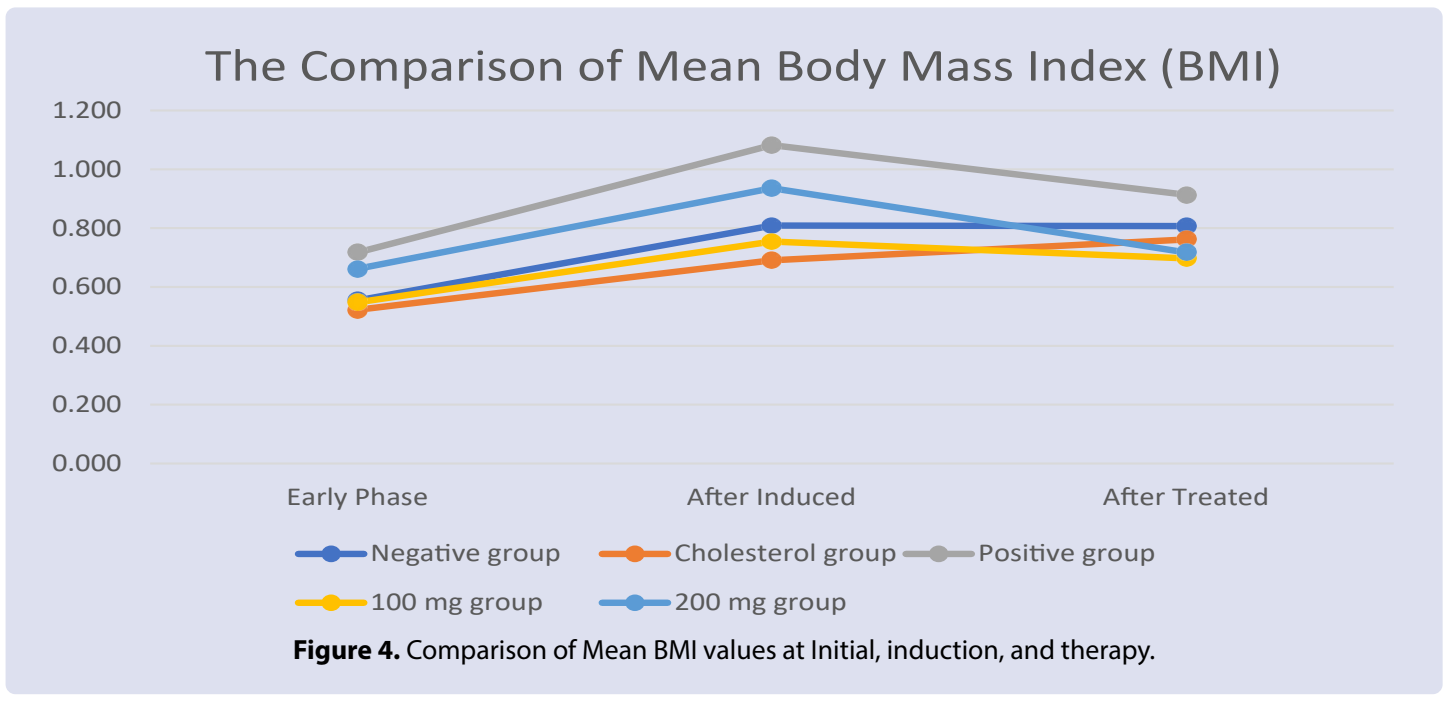

\section{Comparison of Mean Fat Weight}

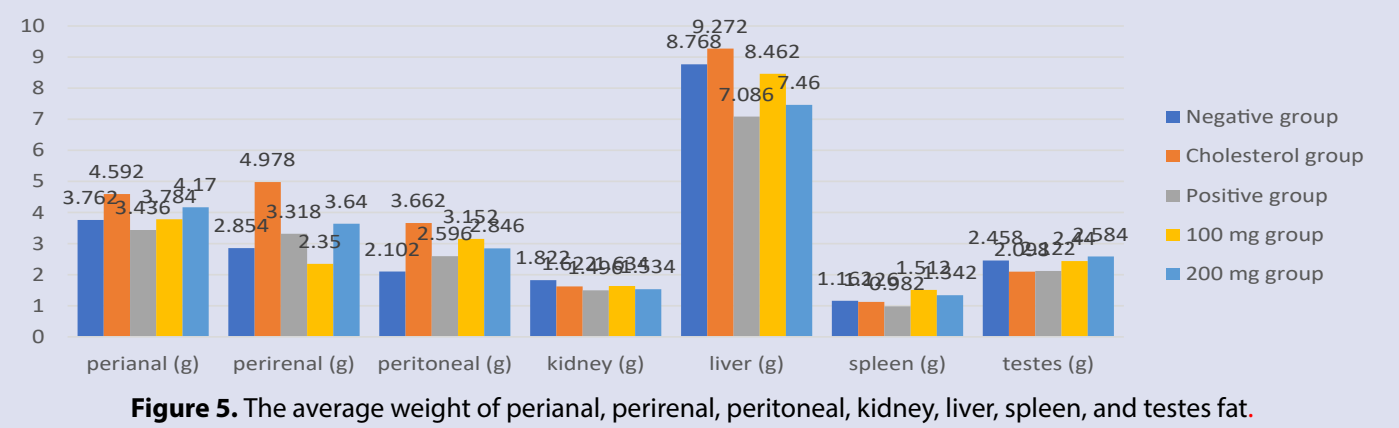

\section{ACKNOWLEDGMENTS}

The authors would like to thank the Ministry of Higher of Research and Highest Education of Indonesia for financial support through PDUPT research sceme (No.Kontrak Induk 169/E4.1/AK.04.PT/2021). The authors also acknowledge Universitas Muslim Indonesia (UMI) for providing necessary laboratory equipment and important facilities to this work.

\section{CONFLICTS OF INTEREST}

The authors declared no conflicts of interest.

\section{REFERENCES}

1. Dabbou, S.; Lahbib, K.; Pandino, G.; Dabbou, S.; Lombardo, S., Evaluation of Pigments, Phenolic and Volatile Compounds, and Antioxidant Activity of a Spontaneous Population of Portulaca oleracea L. Grown in Tunisia. Agriculture 2020, 10 (8).

2. Ajay, K.; Sajana, S.; Arun Kumar, K.; Pardeep, S.; Nirala, R., A review on bioactive phytochemicals, ethnomedicinal and pharmacological importance of Purslane (Portulaca oleracea L.). Research Square 2021.

3. Fawwaz, M.; Pratama, M.; Hasrawati, A.; Widiastuti, H.; Abidin, Z., Total Carotenoids, Antioxidant and Anticancer Effect of Penaeus monodon Shells Extract. Biointerface Research in Applied Chemistry 2021, 11 (4), 11293 - 11302.

4. Simopoulos, A. P.; Norman, H. A.; Gillaspy, J. E.; Duke, J. A., Common purslane: a source of omega-3 fatty acids and antioxidants. J Am Coll Nutr 1992, 11 (4), 374-82.
5. Uddin, M. K.; Juraimi, A. S.; Hossain, M. S.; Nahar, M. A. U.; Ali, M. E.; Rahman, M. M., Purslane weed (Portulaca oleracea): a prospective plant source of nutrition, omega-3 fatty acid, and antioxidant attributes. ScientificWorldJournal 2014, 2014, 951019-951019.

6. Besong, S.; Jackson, J. A.; Trammell, D. S.; Akay, V., Influence of supplemental chromium on concentrations of liver triglyceride, blood metabolites and rumen VFA profile in steers fed a moderately high fat diet. J Dairy Sci 2001, 84 (7), 1679-85.

7. Farkhondeh, T.; Samarghandian, S., The therapeutic effects of Portulaca oleracea L. in hepatogastric disorders. Gastroenterología y Hepatología (English Edition) 2019, 42 (2), 127-132.

8. Rahimi, V. B.; Ajam, F.; Rakhshandeh, H.; Askari, V. R., A Pharmacological Review on Portulaca oleracea L.: Focusing on AntiInflammatory, Anti- Oxidant, Immuno-Modulatory and Antitumor Activities. J Pharmacopuncture 2019, 22 (1), 7-15.

9. Zhou, Y. X.; Xin, H. L.; Rahman, K.; Wang, S. J.; Peng, C.; Zhang, H., Portulaca oleracea L.: a review of phytochemistry and pharmacological effects. Biomed Res Int 2015, 2015, 925631.

10. Zhou, Y.-X.; Xin, H.-L.; Rahman, K.; Wang, S.-J.; Peng, C.; Zhang, $\mathrm{H}_{\text {., }}<\mathrm{i}>$ Portulaca oleracea</i> L.: A Review of Phytochemistry and Pharmacological Effects. BioMed Research International 2015, 2015, 925631.

11. Uddin, M. K.; Juraimi, A. S.; Ali, M. E.; Ismail, M. R., Evaluation of Antioxidant Properties and Mineral Composition of Purslane (Portulaca oleracea L.) at Different Growth Stages. International Journal of Molecular Sciences 2012, 13 (8).

12. Kumar, S.; Kelly, A. S., Review of Childhood Obesity: From Epidemiology, Etiology, and Comorbidities to Clinical Assessment and Treatment. Mayo Clin Proc 2017, 92 (2), 251-265. 
13. Agra, M. F.; Silva, K. S. N.; Basillio, I.; Freitas, P. F. d.; BarbosaFilho, J., Survey of medicinal plants used in the region Northeast of Brazil. Revista Brasileira De Farmacognosia-brazilian Journal of Pharmacognosy 2008, 18, 472-508.

14. Gong, F.; Li, F.; Zhang, L.; Li, J.; Zhang, Z.; Wang, G., Hypoglycemic effects of crude polysaccharide from Purslane. International journal of molecular sciences 2009, 10 (3), 880-888.

15. Rashed, A. N.; Afifi, F. U.; Shaedah, M.; Taha, M. O., Investigation of The Active Constituents of Portulaca Oleraceae L. (Portulacaceae) Growing in Jordan Pakistan Journal of Pharmaceutical Sciences 2004, 17 (1), 37-45.

16. Newary, E.; Ali, S., Hypolipidemic effect of Portulaca oleracea L. stem on hyperlipidemic Wister Albino rats Annals of agricultural science 2016, 61 (8).

17. Nazeam, J. A.; El-Hefnawy, H. M.; Omran, G.; Singab, A.-N., Chemical profile and antihyperlipidemic effect of Portulaca oleracea L. seeds in streptozotocin-induced diabetic rats. Natural Product Research 2018, 32 (12), 1484-1488.

18. Shafi, S.; Tabassum, N., Evaluation of Antidiabetic and Hypolipidemic Activities of Ethanolic Extract of Portulaca oleracea (Whole Plant) in Alloxan Induced Diabetic Rats. International Journal of Pharmaceutical Sciences Review and Research 2016, 38 (2), 64-69.

19. Pragda, S. S.; Kuppast, I.; Mankani, K.; L, R., Evaluation of Antihyperlipidemic Activity of Leaves of Portulaca Oleracea Linn Against Dexamethasone Induced Hyperlipidemia in Rats International Journal of Pharmacy and Pharmaceutical Sciences 2012, 4, 279-283.

20. Bakar, M. F. A.; Ahmad, N. E.; Karim, F. A.; Saib, S., Phytochemicals and Antioxidative Properties of Borneo Indigenous Liposu (Baccaurea lanceolata) and Tampoi (Baccaurea macrocarpa) Fruits. Antioxidants (Basel) 2014, 3 (3), 516-525.

21. Singleton, V. L.; Orthofer, R.; Lamuela-Raventós, R. M., Analysis of total phenols and other oxidation substrates and antioxidants by means of folin-ciocalteu reagent. In Methods in Enzymology, Academic Press: 1999; Vol. 299, pp 152-178.

22. Abuzaid, A. S.; Sukandar, E. Y.; Kurniati, N. F.; Adnyana, I. K., Preventive Effect on Obesity of Mangosteen (Garcinia Mangostana L.) Pericarp Ethanolic Extract by Reduction of Fatty Acid Synthase Level in Monosodium Glutamate and High-Calorie Diet-Induced Male Wistar Rats. Asian Journal of Pharmaceutical and Clinical Research 2016, 9 (3), 257-260.
23. Changizi-Ashtiyani, S.; Zarei, A.; Taheri, S.; Rasekh, F.; Ramazani, M., The Effects of Portulaca Oleracea Alcoholic Extract on Induced Hypercholesteroleomia in Rats. Zahedan J Res Med Sci 2013, 15 (6), e92959.

24. Manna, P.; Jain, S. K., Obesity, Oxidative Stress, Adipose Tissue Dysfunction, and the Associated Health Risks: Causes and Therapeutic Strategies. Metab Syndr Relat Disord 2015, 13 (10), 423-444.

25. Abdali, D.; Samson, S. E.; Grover, A. K., How effective are antioxidant supplements in obesity and diabetes? Med Princ Pract 2015, 24 (3), 201-215.

26. Zhang, Y.-J.: Gan, R.-Y.; Li, S.; Zhou, Y.: Li, A.-N.; Xu, D.-P.; Li, H.B., Antioxidant Phytochemicals for the Prevention and Treatment of Chronic Diseases. Molecules 2015, 20 (12), 21138-21156.

27. $\mathrm{Xu}, \mathrm{X} . ; \mathrm{Yu}, \mathrm{L} . ;$ Chen, G., Determination of flavonoids in Portulaca oleracea L. by capillary electrophoresis with electrochemical detection. Journal of Pharmaceutical and Biomedical Analysis 2006, 41 (2), 493-499.

28. Anghel, A. I.; Olaru, O.; Gatea, F.; Dinu, M.; Viorel, R.; Istudor, V.; Departament, P. In Preliminary Research on Portulaca Grandiflora Hook. Species (Portulacaceae) for Therapeutic Use, 2013.

29. Lobo, V.; Patil, A.; Phatak, A.; Chandra, N., Free radicals, antioxidants and functional foods: Impact on human health. Pharmacogn Rev 2010, 4 (8), 118-126.

30. Al-Suwailem, A.; Al-Tamimi, A.-M. S.; Al-Omar, M. A.; Al-Suhibani, M. S. In Safety and Mechanism of Action of Orlistat (Tetrahydrolipstatin) as the First Local Antiobesity Drug, 2006.

31. Han, L.-K.; Zheng, Y.-N.; Yoshikawa, M.; Okuda, H.; Kimura, Y., Antiobesity effects of chikusetsusaponins isolated from Panax japonicus rhizomes. BMC Complementary and Alternative Medicine 2005, 5 (1), 9

32. Alpers, D., Role of lipoprotein lipase in triglyceride metabolism: potential therapeutic target. Future Lipidology 2017, 3 (4), 385-397.

33. Gammone, M. A.; Riccioni, G.; D'Orazio, N., Carotenoids: potential allies of cardiovascular health? Food Nutr Res 2015, 59, 26762-26762.

34. Alves-Bezerra, M.; Cohen, D. E., Triglyceride Metabolism in the Liver Compr Physiol 2017, 8 (1), 1-8.

35. Wilding, E. I.; Brown, J. R.; Bryant, A. P.; Chalker, A. F.; Holmes, D. J.; Ingraham, K. A.; Iordanescu, S.; So, C.Y.; Rosenberg, M.; Gwynn, M. N., Identification, evolution, and essentiality of the mevalonate pathway for isopentenyl diphosphate biosynthesis in gram-positive cocci. J Bacteriol 2000, 182 (15), 4319-4327.

\section{GRAPHICAL ABSTRACT}
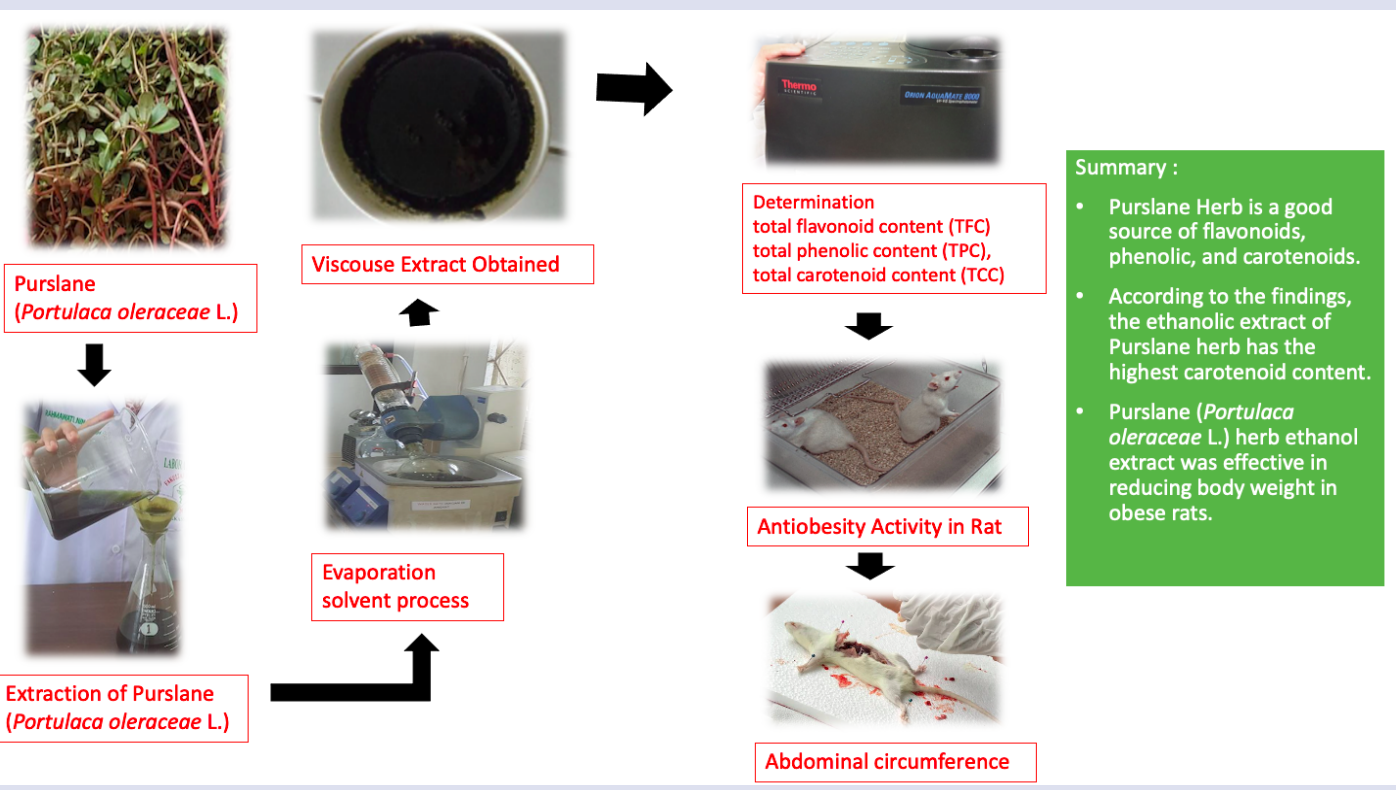


\section{ABOUT AUTHORS}

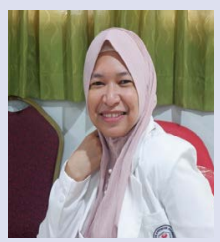

Rizqi Nur Azizah,Worked as an Assistant Professor at Faculty of Pharmacy of Universitas Muslim Indonesia since 2009. She graduated in 2015 from the Magister of Pharmacy Science, University of Indonesia and currently focuses on research related to Pharmacology and Clinical Pharmacy. While serving as a lecturer, she has made many contributions including in the field of research and publications both in national and international journals, as well as being active in Community Service activities and as oral presenters at national and international seminars. She has conducted research and published the results of her research, especially in the field of pharmacology, clinical pharmacy and natural product.

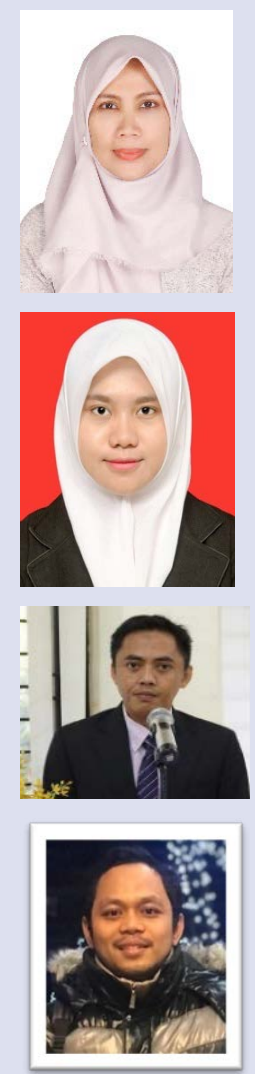

Dr. Andi Emelda is an Associate Professor at Department of Pharmacology, Faculty of Pharmacy, Universitas Muslim Indonesia, South Sulawesi, Indonesia. She has experiences in Pharmacology and Clinical Pharmacy. Her research interest includes drug discovery of natural products, immunomodulatory, degenerative diseases, and screening activity.

Ira Asmaliani, a lecturer and researcher at Department of Biopharmacy-Pharmacology, Faculty of Pharmacy, Universitas Muslim Indonesia, Makassar, South Sulawesi, Indonesia. She has experience in the area pharmacology of natural product research, mainly immunology.

Dr. Islamudin Ahmad, Associate Professor at Department of Pharmaceutical Sciences, Faculty of Pharmacy, Universitas Mulawarman, East Kalimantan, Indonesia. He has experience in Pharmacognosy and Natural Product Chemistry, working in drug discovery of natural products, green extraction engineering, isolation and identification of active compounds, screening activity, and mainly degenerative diseases.

Muammar Fawwaz obtained his Ph.D in pharmaceutical sciences in 2021 from Kanazawa University, Japan. Currently, he is an assistant professor at the Laboratory of Pharmaceutical Chemistry, Universitas Muslim Indonesia, Makassar, Indonesia. His research focuses on development of the molecular probes from synthesis organic chemistry and medicinal plant for cancer imaging and therapy.

Cite this article: Azizah RN, Emelda A, Asmaliani I, Ahmad I, Fawwaz M. Total Phenolic, Flavonoids, and Carotenoids Content and Anti-Obesity Activity of Purslane Herb (Portulaca oleracea L.) Ethanol Extract. Pharmacogn J. 2022;14(1): 8-13. 